\title{
Antinociceptive effects of the essential oil of Mentha $x$ villosa leaf and its major constituent piperitenone oxide in mice
}

\author{
P.J.C. Sousa', C.F.B.M. Linard², D. Azevedo-Batista², A.C. Oliveira², \\ A.N. Coelho-de-Souza ${ }^{2}$ and J.H. Leal-Cardoso ${ }^{2}$ \\ 1Departamento de Farmácia, Centro de Ciências da Saúde, Universidade Federal do Pará, Belém, PA, Brasil \\ ${ }^{2}$ Instituto Superior de Ciências Biomédicas, Universidade Estadual do Ceará, Fortaleza, CE, Brasil
}

\begin{abstract}
Mentha $\mathrm{x}$ villosa Huds (Labiatae) is an aromatic herb widely used in folk medicine. Since the essential oil of the herb has many pharmacological activities, including antispasmodic effects, we determined whether the oil and its major constituent, piperitenone oxide (PO), have antinociceptive activity. The essential oil of $M$. $x$ villosa (EOMV) and PO administered orally at $200 \mathrm{mg} / \mathrm{kg}$ (vehicle: $0.1 \%$ Tween 80 in water) significantly reduced the writhings induced by acetic acid from control values of $59.5 \pm 3.1$ $\mathrm{s}(\mathrm{N}=10)$ to $31.9 \pm 2.8 \mathrm{~s}(\mathrm{~N}=10)$ and $23.8 \pm 3.4 \mathrm{~s}(\mathrm{~N}=10)$, respectively. When administered at $100 \mathrm{and} 200 \mathrm{mg} / \mathrm{kg}$, EOMV reduced the paw licking time for the second phase of the formalin test from the control value of $20.6 \pm 2.1 \mathrm{~s}(\mathrm{~N}=13)$ to $5.3 \pm$ $2.2 \mathrm{~s}(\mathrm{~N}=12)$ and $2.7 \pm 1.2 \mathrm{~s}(\mathrm{~N}=18)$, respectively. At 100 and $200 \mathrm{mg} / \mathrm{kg}, \mathrm{PO}$ reduced this second phase to $8.3 \pm 2.7 \mathrm{~s}(\mathrm{~N}=$ 12 ) and $3.0 \pm 1.2 \mathrm{~s}(\mathrm{~N}=10)$, respectively. This effect of EOMV and PO was not reversed by naloxone. EOMV and PO had no significant effect on the first phase of the formalin test. As evaluated by the hot-plate and tail immersion test, EOMV and PO, at doses up to $200 \mathrm{mg} / \mathrm{kg}$, showed no analgesic activity. These results show that EOMV and PO have antinociceptive activity and suggest that this effect is probably an indirect anti-inflammatory effect, which does not involve the central nervous system.
\end{abstract}

Key words: Mentha x villosa essential oil; Analgesia; Nociception; Anti-inflammatory effect; Piperitenone oxide

\section{Introduction}

Many mentha species are used all over the world as coleretic, spasmolytic, and analgesic agents (1). In the Northeast of Brazil, Mentha $x$ villosa Huds (Labiatae), an aromatic herb, is widely used in folk medicine as a stomachic and anxiolytic agent, and for the treatment of menstrual cramps and diarrhea with colic and blood in the stools (2). Its leaves also are used to flavor food.

Earlier studies with Mentha $x$ villosa have reported its antiparasitic activity in amebiasis, giardiasis, and urogenital trichomoniasis (3). In our laboratory, we have shown that the essential oil of $M . x$ villosa (EOMV) blocks excitationcontraction coupling in skeletal muscle and causes contraction by releasing $\mathrm{Ca}^{2+}$ from the sarcoplasmic reticulum (4). Piperitenone oxide (PO), the major constituent of
EOMV, exerts an antispasmodic effect on the intestinal smooth muscle of guinea pigs (5). In conscious rats, intravenous administration of EOMV elicited immediate and dose-dependent decreases in mean aortic pressure and heart rate (6). Pretreatment of rats with hexamethonium reduced the EOMV-induced bradycardia without affecting the hypotension and suggested that the activity of this essential oil has neural and myogenic components (6). In both DOCA-salt-hypertensive and uninephrectomized control conscious rats, EOMV decreased mean aortic pressure and heart rate in a dose-dependent manner, and its action in hypertensive animals was enhanced compared to the uninephrectomized controls (7). The major constituent of EOMV has been reported to induce a significant and dose-

Correspondence: J.H. Leal-Cardoso, Instituto Superior de Ciências Biomédicas, Universidade Estadual do Ceará, Av. Paranjana, 1700, Campus Itaperi, 60740-000 Fortaleza, CE, Brasil. Fax: +55-85-3101-9810. E-mail: lealcard@gmail.com

Research supported by CNPq, CAPES, FUNCAP, Colégio Christus. Received July 10, 2008. Accepted May 19, 2009. 
dependent hypotension and bradycardia in unanesthetized normotensive rats (8).

The biological activities of Mentha $x$ villosa and the extensive use of this herb in folk medicine to treat colic, has prompted us to extend our investigations of EOMV and PO to its analgesic activity. We show that both these agents have an antinociceptive effect, which is not mediated by opioid receptors.

\section{Material and Methods}

Mentha $x$ villosa was collected in January 1997 at the experimental farm of Universidade Federal do Ceará (UFC), Pentecostes, CE, Brazil. Its botanical identity was determined by Dr. Francisco J. Abreu Matos (Laboratório de Produtos Naturais, UFC) and Dr. Raymond Harley (Royal Botanic Garden, UK). A voucher specimen (\#27286) is deposited in the Prisco Bezerra herbarium (UFC).

EOMV and PO were prepared and provided by Dr. Sergio Horta (experimental farm of the UFC) and analyzed in the Laboratório de Produtos Naturais and the Parque de Desenvolvimento Tecnológico (PADETEC) of UFC. EOMV (yield: $0.5 \mathrm{~mL} / 100 \mathrm{~g}$ leaves) was extracted from fresh chopped plant leaves by steam distillation and analyzed chemically as previously described (6). PO was obtained from a particular sample of EOMV, which was rich in $\mathrm{PO}$ content. This sample was analyzed by gas chromatography and mass spectrometry (GC-MS) and was shown to be a unique compound, which was identified as piperitenone oxide (98\%). PO ( $\mathrm{m} / \mathrm{z} 166.1)$ was characterized as PO based on its mass spectrum compared with data based on the literature (6). PO was recovered from water by extraction with dichloromethane and evaporation of dichloromethane. The absence of dichloromethane was confirmed by GC/ MS analysis. Briefly, analytical conditions were as follows: EOMV and PO analyses were done on a Hewlett-Packard 6971 GC/MS. Column: dimethylpolysiloxane DB-1 fused silica capillary column (30 m x $0.25 \mathrm{~mm}$; $0.1 \mu \mathrm{m})$; carrier gas: helium ( $1 \mathrm{~mL} / \mathrm{min}$ ); injector temperature: $250^{\circ} \mathrm{C}$; detector temperature: $200^{\circ} \mathrm{C}$; column temperature: $35-180^{\circ} \mathrm{C}$ at $4^{\circ} \mathrm{C} / \mathrm{min}$ and then $180-250^{\circ} \mathrm{C}$ at $10^{\circ} \mathrm{C} / \mathrm{min}$; mass spectra: electronic impact $70 \mathrm{eV}$. The composition of EOMV was $79.03 \%$ piperitenone oxide, $2.82 \% \beta$-cariophyllene, $2.38 \%$ limonene, $2.29 \%$ cariophyllene oxide; $2.18 \%$ y-muurolene, 1.58\% 1,8-cineole, $1.42 \% \beta$-pinene, $0.89 \%$ calamenene (Z), 0.68\% a-humelene, 0.59\% muurole-4(14),5-diene(Z), $0.59 \% \quad \beta$-farnesene (E), 0.57\% $\alpha$-muurolol-epi, $0.4 \%$ $\alpha$-pinene, $0.4 \%$ germecrene $A, 0.86 \%$ not identified, and $3.32 \%$ impurities. These compounds were identified using a mass spectral library search and ${ }^{13} \mathrm{C}-\mathrm{NMR}$ spectroscopy.

Solutions of EOMV and PO were prepared daily by add- ing these substances directly to the vehicle $(0.1 \%$ Tween 80 in water) with 3-5 min vigorous manual agitation or by vortexing the agent in vehicle. The final agent concentration was selected so as to maintain the volume administered to a given animal at $0.1 \mathrm{~mL}$ solution $/ 10 \mathrm{~g}$ body weight.

Morphine was obtained from Cristália (Brazil); Tween 80, naloxone, and dextran, from Sigma Chemical Co. (USA); acetic acid and formalin were from Reagen (Brazil).

All experiments were carried out in accordance with current guidelines for the care of laboratory animals and ethical guidelines for investigations of experimental pain in conscious animals (9). Male Swiss mice (20-30 g) kindly provided by the vivarium of the Universidade Federal do Ceará were used. The animals were deprived of food, with free access to drinking water for $12 \mathrm{~h}$ before the experiments. The number of animals in each control and experimental group varied from 8 to 18 .

The writhing test was carried out according to a method similar to that previously described (10). Briefly, $0.1 \mathrm{~mL} / 10$ $\mathrm{g}$ body weight of an aqueous acetic acid solution $(0.6 \%$, $\mathrm{v} / \mathrm{v}$ ) was administered by the intraperitoneal route and the number of abdominal writhings was counted from the 10th to the 30th min after this administration. EOMV and PO solubilized in vehicle ( $1 \%$ Tween 80 , aqueous solution) were administered by gavage with an orogastric cannula. Naloxone (2 mg/kg body weight), an opioid antagonist, was administered subcutaneously 15 min prior to treatment with EOMV, PO or morphine $(10 \mathrm{mg} / \mathrm{kg}$ body weight, intraperitoneal route). Morphine was administered $30 \mathrm{~min}$ and EOMV or PO 50 min before acetic acid.

The formalin test was carried out as described by Hunskaar et al. (11). Briefly, $20 \mu \mathrm{L}$ of a $1 \%(\mathrm{v} / \mathrm{v})$ solution of formalin in water was injected into the subplantar region of the right paw and the total time the animal spent licking its paw during the first $5 \mathrm{~min}$ (early phase) and from the 20th to the 25th (late phase) min after injection was recorded. The test was carried out at room temperature maintained at $22-26^{\circ} \mathrm{C}$ and care was taken to avoid environmental disturbances and experimental procedures that might interfere with the response of the animal. EOMV, PO, morphine, and naloxone were administered as described for the writhing test.

The hot-plate test was carried out as described by Bannon and Malmberg (12). Briefly, a mouse was placed on top of a plate maintained at a temperature of $50.0 \pm 0.5^{\circ} \mathrm{C}$ and the latency of the reaction to this nociceptive stimulus (number of seconds for the animal to start licking the paw of the caudal limb or jumping) was measured. Only mice that in a previous test had shown a hot-plate reaction time of $20 \mathrm{~s}$ or less were utilized for this test. The latency of the reaction to nociception was measured at $0,30,60,90$, and $120 \mathrm{~min}$. 
The tail immersion test (13) was carried out as follows. After immobilization, $5 \mathrm{~cm}$ of the distal segment of the tail was introduced in a beaker containing water maintained at $50.0 \pm 0.5^{\circ} \mathrm{C}$ and the time (s) required for the mouse to withdraw its tail from the hot water was determined. This procedure was done immediately before ( $0 \mathrm{~min}$ ) and at 30 , 60 , and 90 min after peroral administration of EOMV or PO or intraperitoneal administration of morphine.

The open field test was carried out as follows. Mice were observed for locomotion in an open-field apparatus as described earlier (14). Briefly, each animal was placed in the center of an open-field arena, and a person who was unaware of the treatments counted the locomotion frequency (the number of times the animal crossed the line separating two floor units with all four paws) for a period of $4 \mathrm{~min}, 60 \mathrm{~min}$ after oral administration of EOMV or PO (200 mg/kg body weight) or vehicle $(0.1 \%$ Tween 80 in distilled water).

The rotarod test was performed according to Ref. 15. Briefly, the mice were placed on a horizontal bar with a diameter of $5 \mathrm{~cm}$, subdivided into four compartments (INSIGHT, RR-2002, Brazil) rotating at a speed of $4 \mathrm{rpm}$. Mice that were able to remain on the rod for more than $60 \mathrm{~s}$ were selected $24 \mathrm{~h}$ before the test. Mice ( $\mathrm{N}=8$ per group) were treated orally with vehicle or EOMV or PO $(200 \mathrm{mg} /$ $\mathrm{kg}$ body weight) and 60 min later each animal was tested on the rotarod for its ability to remain on the rod during a 60-s period.

Data are reported as means \pm SEM, with $\mathrm{N}$ indicating the number of animals in each group. Data were analyzed by one-way ANOVA, followed by the most appropriate post hoc test, as suggested by the Sigma Stat (Systat Software, USA) used to analyze the data. Differences were considered to be significant when $P \leq 0.05$.

\section{Results}

When administered at $200 \mathrm{mg} / \mathrm{kg}$ body weight, EOMV and $\mathrm{PO}$ significantly ( $\mathrm{P} \leq 0.05$, Student-Newman-Keuls test) reduced the number of writhings induced by acetic acid in the writhing test from $59.5 \pm 3.1 \mathrm{~s}(\mathrm{~N}=10$, control value) to $31.9 \pm 2.8 \mathrm{~s}(\mathrm{~N}=10)$ and $23.8 \pm 3.4 \mathrm{~s}(\mathrm{~N}=10)$, respectively (Figure 1). At lower doses (10 and $100 \mathrm{mg} / \mathrm{kg}$ body weight), neither agent induced significant changes in the number of writhings. In mice treated with morphine, the number of acetic acid-induced contortions was $3.43 \pm$ $1.21(\mathrm{~N}=8)$ and differed significantly $(\mathrm{P}<0.05$, ANOVA and Holm-Sidak $t$-test)) from control $(64.3 \pm 2.6, N=8)$. In animals treated with naloxone the number of contortions after the administration of $10 \mathrm{mg} / \mathrm{kg}$ morphine, $200 \mathrm{mg} / \mathrm{kg}$ EOMV, or $200 \mathrm{mg} / \mathrm{kg}$ PO was $59.29 \pm 1.96(\mathrm{~N}=8), 33.57$ \pm 2.38 , and $25.10 \pm 3.19(N=8)$, respectively. Naloxone increased significantly the number of contortions in the morphine group compared to the control value but did not alter the number in the EOMV or PO groups compared to control ( $P>0.05$, ANOVA and Holm-Sidak $t$-test).

EOMV administered at 100 and $200 \mathrm{mg} / \mathrm{kg}$ reduced significantly ( $P \leq 0.05$, ANOVA, Dunn test) the paw licking time for the second phase of the formalin test from the control value of $20.6 \pm 2.1 \mathrm{~s}(\mathrm{~N}=13)$ to $5.3 \pm 2.2 \mathrm{~s}(\mathrm{~N}=$ 12) and $2.7 \pm 1.2 \mathrm{~s}(\mathrm{~N}=18)$, respectively. At 100 and 200 $\mathrm{mg} / \mathrm{kg}, \mathrm{PO}$ reduced this second phase to $8.3 \pm 2.7 \mathrm{~s}(\mathrm{~N}=$ 12) and $3.0 \pm 1.2 \mathrm{~s}(\mathrm{~N}=10)$, respectively (Figure 2). This effect of EOMV and $\mathrm{PO}$ was not reversed by naloxone. At lower doses (50 mg/kg body weight), neither agent induced significant changes in the second phase of this test. EOMV and $\mathrm{PO}$ had no significant effect on the first phase of the formalin test at any of the concentrations employed.

The latency times for the reaction to the hot-plate noxious stimulation at the 0th, 30th, 60th, 90th, and 120th min after vehicle administration (control) were: $17.79 \pm 0.98,18.21$ $\pm 1.23,14.21 \pm 0.93,16.58 \pm 1.16$, and $16.37 \pm 1.21 \mathrm{~s}$, respectively ( $N=10$ in all cases). Upon administration of 200 $\mathrm{mg} / \mathrm{kg}$ EOMV, the latency times at $0,30,60,90$, and 120 $\min$ were $16.42 \pm 0.95,16.91 \pm 1.46,16.62 \pm 0.56,17.91$ \pm 1.39 , and $14.95 \pm 1.69 \mathrm{~s}$, respectively; after $200 \mathrm{mg} / \mathrm{kg}$ PO they were $16.12 \pm 1.21,14.52 \pm 1.05,16.55 \pm 0.83$, $16.27 \pm 1.02$, and $15.36 \pm 0.71 \mathrm{~s}$ (values not significantly different from control) ( $P<0.05$; ANOVA, Dunn test; $N=10$ in all cases). Similar results were obtained with $100 \mathrm{mg} / \mathrm{kg}$ EOMV and PO. Latency times were significantly increased by $10 \mathrm{mg} / \mathrm{kg}$ morphine ( $P<0.05$; ANOVA, Dunn test) at

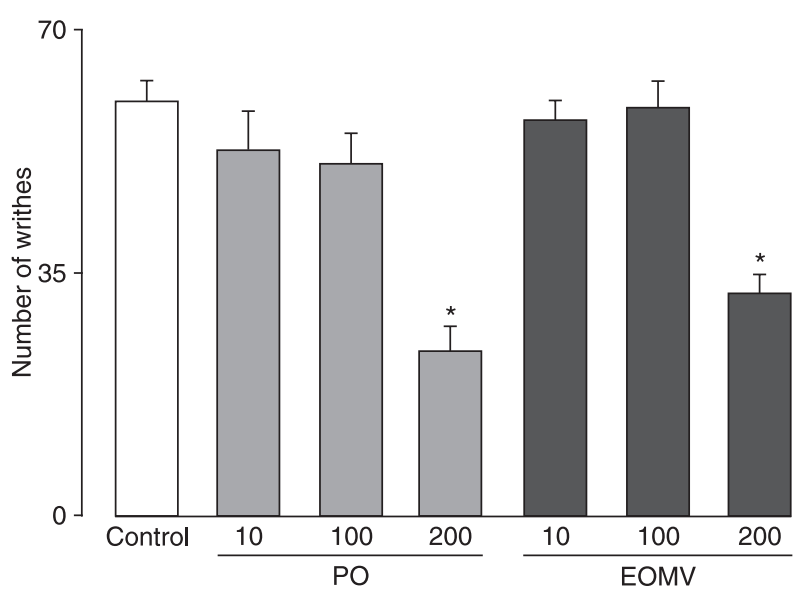

Figure 1. Inhibitory effect of the essential oil of Mentha $x$ villosa (EOMV) and piperitenone oxide (PO) on the nociceptive reaction to intraperitoneal acetic acid injection in mice. Data are reported as the mean number of writhings ( \pm SEM) after oral administration of $\mathrm{PO}$ and EOMV in 10 animals per group. ${ }^{*} \mathrm{P} \leq 0.05 \mathrm{com}-$ pared to the control (ANOVA and Dunn test). 
30,60 , and $90 \mathrm{~min}$ to $39.2 \pm 3.91,39.50 \pm 3.69$, and 36.5 $\pm 3.95 \mathrm{~s}(\mathrm{~N}=10)$, respectively.

The latency times for mouse tail withdrawal after tail immersion in water at $55^{\circ} \mathrm{C}$ at $0,30,60$, and $90 \mathrm{~min}$ after vehicle administration (control, 10 experiments) were: $12.1 \pm 1.81,12.8 \pm 1.76,13.7 \pm 1.79$, and $14.9 \pm 1.52 \mathrm{~s}$, respectively. Upon administration of $200 \mathrm{mg} / \mathrm{kg}$ body weight EOMV, latency times at $0,30,60$, and 90 min after drug administration were $12.73 \pm 1.12,13.11 \pm 1.38,12.98 \pm 0.97$, and $14.05 \pm 1.33 \mathrm{~s}$, respectively; after the administration of $200 \mathrm{mg} / \mathrm{kg}$ body weight $\mathrm{PO}$ they were $12.35 \pm 1.01,13.21$ $\pm 1.67,13.07 \pm 1.92$, and $15.09 \pm 1.52 \mathrm{~s}$ (values not significantly different from control; $P<0.05$; ANOVA, Dunnett
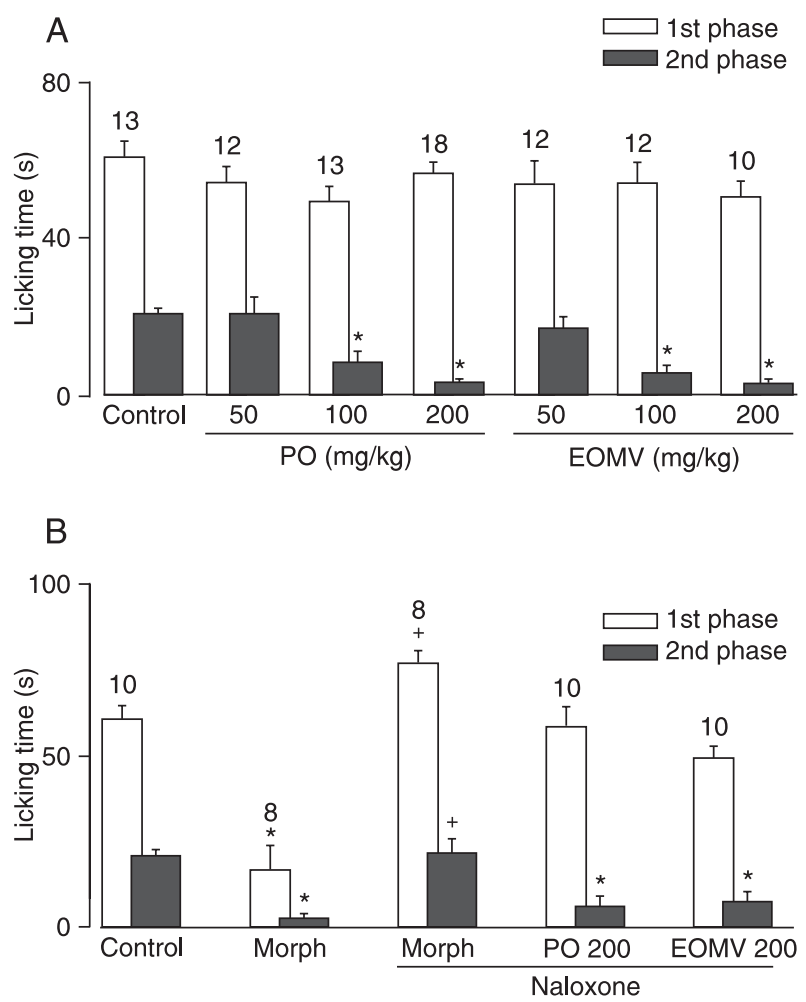

Figure 2. Inhibitory effect of the essential oil of Mentha $x$ villosa (EOMV) and piperitenone oxide (PO) on the nociceptive reaction to intraplantar formalin injection. A, Effect of EOMV and PO (50, 100 , and $200 \mathrm{mg} / \mathrm{kg}$ body weight) on the time spent licking the paw in the first and second phases of the nociceptive reaction. $B$, Absence of alteration by $2 \mathrm{mg} / \mathrm{kg}$ body weight naloxone administered subcutaneously of the EOMV- and PO-induced effects (200 $\mathrm{mg} / \mathrm{kg}$ body weight) on the time spent licking the paw in the first and second phases of the nociceptive reaction. Morphine (Morph; $10 \mathrm{mg} / \mathrm{kg}$ ) was administered intraperitoneally. Data are reported as mean licking time $\left( \pm\right.$ SEM). ${ }^{*} \mathrm{P} \leq 0.05$ compared to the respective control; ${ }^{+} \mathrm{P} \leq 0.05$ compared to morphine in the absence of naloxone (ANOVA, Dunn test in Panel A and Mann-Whitney rank sum test in Panel B). The numbers above the columns indicate the number of mice in each group. test; $\mathrm{N}=10$ in all cases). Latency times were significantly increased ( $P \leq 0.5$, ANOVA and Dunnett test) by $10 \mathrm{mg} / \mathrm{kg}$ body weight morphine at 30,60 , and 90 min to $26.7 \pm 2.73$, $23.6 \pm 1.49$, and $25.3 \pm 3.01 \mathrm{~s}(\mathrm{~N}=10)$, respectively.

EOMV $(200 \mathrm{mg} / \mathrm{kg})$ or $200 \mathrm{mg} / \mathrm{kg} \mathrm{PO}$ administered orally had no significant effect $(P>0.05$, ANOVA and Holm-Sidak test) on locomotion frequency (control: $64.63 \pm 4.92$; EOMV: $71.62 \pm 11.45$; PO: $56.50 \pm 4.67 ; \mathrm{N}=8$ in all cases) or on motor coordination (time of permanence on the rotarod, control: $60 \mathrm{~s}$; EOMV or PO: $60 \mathrm{~s}$ in all cases; $\mathrm{N}=8$ in each animal group).

\section{Discussion}

The most important finding of the present study is that the essential oil of $M . x$ villosa and piperitenone oxide, its major constituent, showed antinociceptive activity demonstrable by a significant alteration of the acetic acid-induced writhing test and the second phase of the formalin test, while in the same range of doses they did not interfere with the nociception associated with the hot-plate and tail immersion tests. The hot-plate and tail immersion tests are reported to be useful tests to discriminate analgesic agents acting primarily at the spinal medulla level and at higher central nervous system levels, from those acting by peripheral mechanisms, with positive results indicating a central action (16). This suggests that EOMV and $\mathrm{PO}$ are acting by peripheral mechanisms. The formalin test results reinforced this assumption. The two phases of rodent response to formalin have been attributed to different mechanisms (11). The first phase, which was not affected by EOMV or PO, is reported to originate from the stimulation of tissue endings of nociceptor neurons, while the second phase, selectively affected by EOMV and PO, is said to be due to inflammatory activity and/or alteration of central processing. If, based on the results of the hot-plate and tail immersion tests, we assume that the antinociceptive effect of EOMV and PO was not related to central processing, then it stands as an attractive hypothesis that this effect is mainly due to anti-inflammatory activity. This hypothesis is compatible with the results obtained with the acetic acid-induced writhing test. Writhings induced by intra-peritoneal injections of acetic acid are said to originate from the pain associated with the inflammatory reaction (17). An antinociceptive activity of EOMV and PO in this model thus agrees with an anti-inflammatory activity. The antinociceptive effect of EOMV and PO is not likely to be caused by sedation or primary deficit of motor activity. This is because EOMV and $\mathrm{PO}$, at doses that produced the antinociceptive effect, did not alter the motor performances in the open field and rotarod test. This is consistent with 
the fact that the responses of the animal were not altered in the first phase of the formalin test or in the hot-plate and tail immersion tests. The antinociceptive activity induced by EOMV and $\mathrm{PO}$ in the writhing and formalin tests was not altered by naloxone, demonstrating that their actions did not depend on opioid receptors (18), supporting the anti-inflammatory hypothesis for their mechanism of action. Thus, it is reasonable to suggest that EOMV and $\mathrm{PO}$ have an analgesic activity, which, however, is probably indirect, due to an anti-inflammatory activity.

Regarding antinociceptive activity, it is interesting to note that the doses of PO needed to induce these effects were similar to those of EOMV, thus suggesting that $\mathrm{PO}$ is the EOMV constituent largely responsible for these effects.

$M . x$ villosa is used by the people of the Northeast of Brazil as an antispasmodic and antidiarrheic agent. Our laboratory has confirmed in in vitro studies that EOMV and $\mathrm{PO}$ (5) have antispasmodic activity, which is consistent with the use of the plant in folk medicine. In the present study, we are adding to the list of the pharmacological effects of EOMV and PO their potential as therapeutically useful antinociceptive agents. This analgesic activity occurred with $100 \mathrm{mg} / \mathrm{kg}$ body weight. Importantly, at similar doses, $100 \mathrm{mg} / \mathrm{kg}$ body weight EOMV and $80 \mathrm{mg} / \mathrm{kg}$ body weight $\mathrm{PO}$ had no toxic effects when administered to rats for 30 days (19).

\section{Acknowledgments}

We would like to thank Drs. Francisco J.A. Matos and Talapala G. Naidu for discussion and encouragement; Dr. Afranio A. Craveiro, Iracema Lacerda Machado and Sergio Horta Matos, from the Laboratório de Produtos Naturais of the Universidade Federal do Ceará, for encouragement and for kindly providing the EOMV, and Mr. Francisco Evanir G. de Lima for technical assistance.

\section{References}

1. McKay DL, Blumberg JB. A review of the bioactivity and potential health benefits of peppermint tea (Mentha piperita L.). Phytother Res 2006; 20: 619-633.

2. Leal-Cardoso JH, Fonteles MC. Pharmacological effects of essential oils of plants of the northeast of Brazil. An Acad Bras Cienc 1999; 71: 207-213.

3. Santana CF, Almeida ER, Dos Santos ER, Souza LA. Action of Mentha crispa hydroethanolic extract in patients bearing intestinal protozoan. Fitoterapia 1992; 63: 409-410.

4. Fogaça RTH, Cavalcante ADA, Serpa AKL, Sousa PJC, Coelho-de-Souza AN, Leal-Cardoso JH. The effects of essential oil of Mentha $x$ villosa on skeletal muscle of the toad. Phytother Res 1997; 11: 552-557.

5. Sousa PJ, Magalhaes PJ, Lima CC, Oliveira VS, LealCardoso $\mathrm{JH}$. Effects of piperitenone oxide on the intestinal smooth muscle of the guinea pig. Braz J Med Biol Res 1997; 30: 787-791.

6. Lahlou S, Magalhaes PJ, Carneiro-Leao RF, Leal-Cardoso $\mathrm{JH}$. Involvement of nitric oxide in the mediation of the hypotensive action of the essential oil of Mentha $x$ villosa in normotensive conscious rats. Planta Med 2002; 68: 694-699.

7. Lahlou S, Carneiro-Leao RF, Leal-Cardoso JH. Cardiovascular effects of the essential oil of Mentha $x$ villosa in DOCAsalt-hypertensive rats. Phytomedicine 2002; 9: 715-720.

8. Guedes DN, Silva DF, Barbosa-Filho JM, Medeiros IA. Muscarinic agonist properties involved in the hypotensive and vasorelaxant responses of rotundifolone in rats. Planta Med 2002; 68: 700-704.

9. Zimmermann M. Ethical guidelines for investigations of experimental pain in conscious animals. Pain 1983; 16: 109110.

10. Soukupova M, Dolezal T, Krsiak M. The synergistic interaction between rilmenidine and paracetamol in the writhing test in mice. Naunyn Schmiedebergs Arch Pharmacol 2009; 379:
575-580.

11. Hunskaar S, Fasmer OB, Hole K. Formalin test in mice, a useful technique for evaluating mild analgesics. J Neurosci Methods 1985; 14: 69-76.

12. Bannon AW, Malmberg AB. Models of nociception: hot-plate, tail-flick, and formalin tests in rodents. Curr Protoc Neurosci 2007; Chapter 8: Unit 9.1-Unit 9.15.

13. Ghule BV, Murugananthan G, Yeole PG. Analgesic and antipyretic effects of Capparis zeylanica leaves. Fitoterapia 2007; 78: 365-369.

14. Gomes PB, Noronha EC, de Melo CT, Bezerra JN, Neto MA, Lino CS, et al. Central effects of isolated fractions from the root of Petiveria alliacea L. (tipi) in mice. J Ethnopharmacol 2008; 120: 209-214.

15. Rosland JH, Hunskaar S, Hole K. Diazepam attenuates morphine antinociception test-dependently in mice. Pharmacol Toxicol 1990; 66: 382-386.

16. Le Bars D, Gozariu M, Cadden SW. Animal models of nociception. Pharmacol Rev 2001; 53: 597-652.

17. Ribeiro RA, Vale ML, Thomazzi SM, Paschoalato AB, Poole $\mathrm{S}$, Ferreira $\mathrm{SH}$, et al. Involvement of resident macrophages and mast cells in the writhing nociceptive response induced by zymosan and acetic acid in mice. Eur J Pharmacol 2000; 387: 111-118.

18. Williamson EM, Okpako DT, Evans FJ. Anti-inflammatory and analgesic activity. In: Anonymous, Selection, preparation and pharmacological evaluation of plant material. New York: John Wiley and Sons; 1996. p 132-154.

19. Sousa PJC. Estudos farmacológicos do óleo essencial de Mentha $x$ villosa e seu principal constituinte, óxido de piperitenona, em músculos lisos gastrointestinais de cobaia e pressão arterial de rato. [Doctoral thesis]. Fortaleza: Departamento de Fisiologia e Farmacologia, Universidade Federal do Ceará; 1999. 